\section{SJESR}

Sir Syed Journal of Education \& Social Research

\title{
Role of Building Sector in Consumption of Energy in Pakistan
}

\author{
* Yasmeen Abid Maan, Assistant Professor \\ ** Dr. Munazzah Akhtar, Assistant Professor \\ *** Maryam Jamil, Lecturer (Corresponding Author)
}

\begin{abstract}
Energy Efficiency has become an integral necessity at a global scale and with the rapidly escalating population around the world, the energy demand has also amplified to extreme levels, making the provision of energy a real challenge. Henceforth, implementation of more efficient conservative measures must be targeted as the supply of fossil fuels is not infinite and the extensive energy consumption is causing harm to the environment. With the continuously growing demand for energy, and as per the forecast of the International Energy Agency, it is expected that the rise will be up to fifty percent by 2030. Recently, more than eighty percent of primary energy demand is being fulfilled by fossil fuels; and the reservoirs of fossil fuels are fast depleting. The result is climate change at the global level, leading to unprecedented and varied effects on weather events, droughts, and hurricanes in many countries and also flooding in major sectors of the world. It has been realized that fifty percent of the energy produced in the world is utilized by residential buildings. To control the emission of greenhouse gases, it is important to use architectural design techniques to make residential buildings more energy efficient for maintaining the thermal comfort level of occupants.
\end{abstract}

Keywords: Energy Consumption, Residential Buildings, Energy Efficient

Introduction

In Pakistan, more than $25 \%$ of the total electrical supply is consumed by the residential and commercial sectors. The major part of the energy is castoff in operating the constructed buildings. Therefore, techniques for saving energy in buildings are considered to be an important strategy to combat the issue of the energy crisis in Pakistan. Pakistan's energy sector faces severe challenges due to deficient production and an increase in demand. The results estimated by ARDL show that energy consumption increases the $\mathrm{CO}_{2}$ gas emission in Pakistan. Policymakers in the energy sector of Pakistan will have to consider these facts and adopt techniques that are more focused on developing energy-efficient building designs. This will have an absolute assurance for the sustainable economic development of Pakistan.

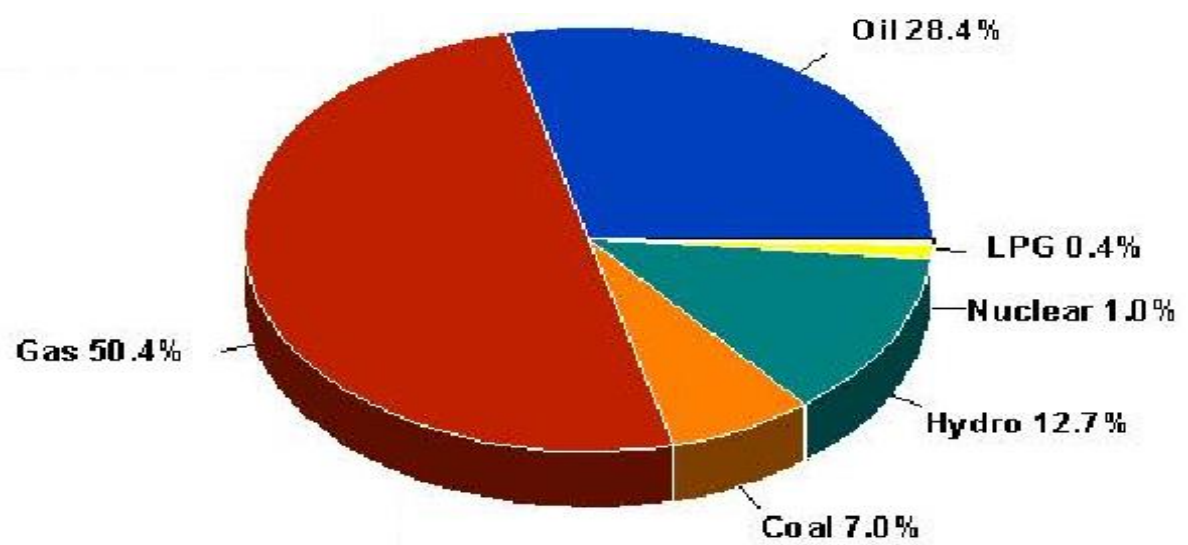

Fig. 1 Energy Resources in Pakistan

At the moment, the Pakistan Water and Power Development Authority (WAPDA) is generating approximately $80 \%$ electricity through oil \& gas power plants (Fig. 1). These plants are not working at the ir full capacity due to a shortage of resources throughout the year. The objective of this

* Architecture Department, Lahore College for Women University, Lahore

** Department of Architecture, University of Engineering \& Technology, Lahore

*** Architecture Department, Lahore College For Women University, Lahore 
article is to study the consumption of electric ity in new ly built residential buildings in Lahore. It is generally observed that during the long-summer season mechanical means are used to maintain a comfortable indoor environment in houses. Therefore, such houses consume a lot of electricity for cooling purposes.

\section{Lite rature Review:}

The Literature review, as developed from books, articles, and reports published, is done to recognize the techniques and materials for relevant incorporation in constructing envelope/fabric of buildings to conserve electricity. Currently, Pakistan is facing the worst electricity crisis of its history gripping the nation. It appears that the gas crisis has finally begun to raise its atrocious head, with frequent reports of low gas pressure, rationing, and closures of CNG stations, leading to load-shedding - affecting the residential and commercial sector.

The energy sector in Pakistan is facing an extreme crisis because of inadequate production, failing to fulfill amplified energy demands in previous years. The major factors of the financial conditions about economic instability present an urgent need for recycling. Oil and natural gas are one of the most dominant energy resources have a dependency of more than $80 \%$ of the energy consumption. The recent constraints have the enormously affected provision of these resources; thus, resulting in inadequate energy production. With the increase in the growth rate of population, estimated around 3\% per year, the demand for energy supply is also increasing. The consumption of natural gas, coal, and petroleum products has not accommodated the surging demands of the country. As per Pakistan Economic Survey, the consumption in the energy sector was 38.8 MTOE (million tonnes of oil equivalent) - increased to the level of 70.5 MOTE for Lahore, where the performance of industries and quality of life of citizens has been hit in particular. The textile industry had claimed they suffered a loss of Rs. 1 Billion due to scarcity of gas supply of industries.

\begin{tabular}{|c|c|c|c|c|c|c|c|c|c|c|c|c|c|}
\hline \multicolumn{14}{|c|}{ Supply and Demand of Electricity in Pakistan } \\
\hline \multicolumn{14}{|c|}{ Supply and Demand Position: 2008-2020 (MW) } \\
\hline & 2008 & 2009 & 2010 & 2011 & 2012 & 2013 & 2014 & 2015 & 2016 & 2017 & 2018 & 2019 & 2020 \\
\hline Existing Generation & 15,903 & 15,903 & 15,903 & 15,903 & 15,903 & 15,903 & 15,903 & 15,903 & 15,903 & 15,903 & 15,903 & 15,903 & 15,903 \\
\hline Proposal/ Committed Generation & 530 & 4,235 & 7,226 & 10,115 & 10,556 & 13,307 & 13,520 & 14,607 & 16,134 & 18,448 & 18,448 & 18,448 & 18,448 \\
\hline TotalExisting/Committed Generation & 16,484 & 20,138 & 23,129 & 26,018 & 26,459 & 29,210 & 29,423 & 30,510 & 32,037 & 34,351 & 34,351 & 34,351 & 34,351 \\
\hline Expected Available Generation & 13,146 & 16,110 & 18,503 & 20,814 & 21,167 & 23,368 & 23,538 & 24,408 & 25,630 & 27,481 & 27,481 & 27,481 & 27,481 \\
\hline Demand (Summer Peak) & 16,484 & 17,868 & 19,352 & 20,874 & 22,460 & 24,126 & 25,919 & 28,029 & 30,223 & 35,504 & 34,918 & 37,907 & 41,132 \\
\hline Surplus/Deficit Generation & $-3,338$ & $-1,758$ & -849 & -60 & $-1,293$ & .758 & $-2,381$ & $-3,621$ & $-4,593$ & $-8,023$ & $-7,437$ & $-10,426$ & $-13,651$ \\
\hline
\end{tabular}

Fig. 2 S upply and Demand of Electricity in Pakistan. Source: Private Power and Infrastructure Board - Govt. of Pakistan

As has been reported, electricity demand is to be amplified at a rate of $7.9 \%$ yearly from 2010 till 2020, and PEPCO has devised electricity load management to control the gap between demand \& supply particularly during summer (Fig. 2). The disaster that the country has faced in these past years, owing to energy-related policies, has led Pakistan to a severe power crisis that only increased the economic burden on the poor. Pakistan like other countries faced issues due to fast growth in population and economic expansion. However, major causes of over-consumption of electricity in homes correspond to illegal and misinterpreted the use of the electricity supplies as corruption, exaggeration, or mismanagement. It has been demonstrated in many research studies that the energy sector encounters major challenges that are relative to economics and sustainability.

\section{Indige nous Techniques to Reduce Energy Consumption in Residential B uildings}

The building designs that do not measure energy consumption in a controlled manner represent relatively irresponsible Architecture. This may include any building typology like a resort building, commercial area, residential complex, or a government sector building as being dependent on mechanical means for maintaining the adequate thermal comfort level inside the buildings. Such designs result in great demand for architectural techniques in the construction of buildings with implementations of energy efficiency and sustainability through all appropriate options such as 'retrofitting' in already constructed buildings, with the objectivity of reducing electricity consumption for making indoors comfortable to live in; as well as modifications in structural elements of a building for the expected decrease in energy usage for cooling or heating purposes. 


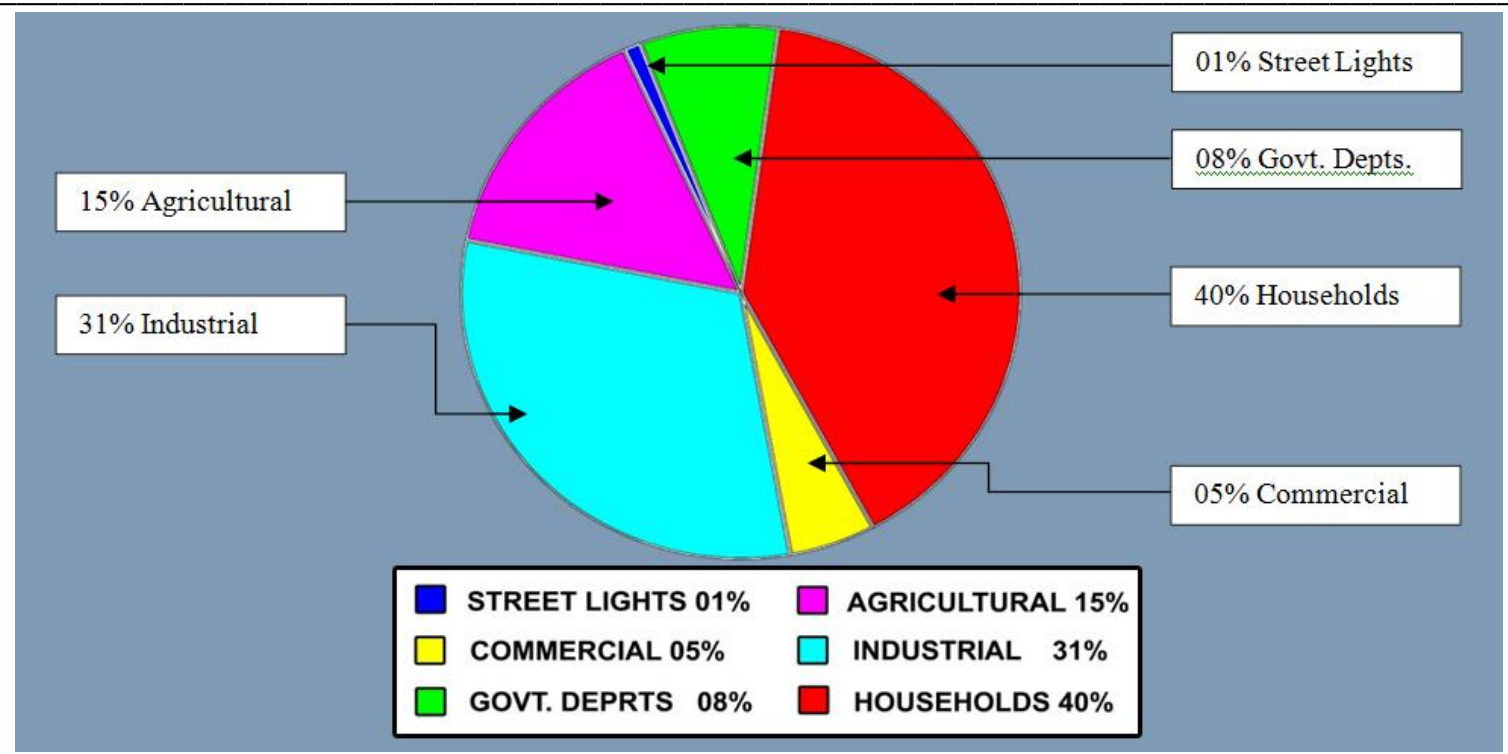

Fig. 3 Electricity Consumption by Various Sectors

As the chart of respective consumption of energy shows (Fig. 3) the residential projects consume maximum electric ity at $40 \%$, then comes to the industry at $31 \%$, agricultural sector at $15 \%$, and commercial sector consuming $5 \%$ of the electricity usage. The residential sector is the largest consumer of electricity supply.

\section{Enercon Directives as Mitigation Measures for B uildings in Pakistan}

1. Encourage and facilitate the audits regarding energy in residential and commercial buildings.

2. Encourage energy-efficient contemplations in domestic life.

3. Building evaluation regarding insulation and insulation materials concerning energy efficiency features.

4. Increase the use of energy-efficient appliances, equipment, and fixtures in buildings.

5. Strategy development/up-gradation of Building Energy Code to measure the compliances in the country.

6. Promote the practice of using energy-efficient lighting fixtures and HVAC systems in buildings.

7. Develop a suitable database/MIS concerning the conservation of energy techniques in buildings.

This study aims to analyze the consumption of electricity in newly built residential buildings in Lahore. It is generally observed that during the long summer season mechanical resources are used to maintain a comfortable indoor environment. Therefore, such houses consume a lot of electricity for cooling purposes. In residential buildings, the heat gained through any building's envelope results in further enhancing the uncomfortable conditions in the interior spaces. Therefore, it is recommended that the selection of materials in the construction should be made concerning the ir potential in making thermal comfort levels as adequate as required by the occupants. The focus will remain on assessing the impact of the building's envelope, ensuring the use of different insulating materials, on the electricity consumption to highlight the potentials of saving electricity.

\section{Research Objectives, Significance, and Methodologies}

A high level of awareness needs to be created towards the efficient use of electricity in residential buildings. A prospective potential of energy conservation ranging from $20-50 \%$ can be anticipated in residential buildings after applying adequate techniques and measures.

The primary objective is to understand electricity consumption trends in newly built residential buildings in a composite climate of Lahore Pakistan. To achieve this objective, the following matters also need consideration:

a. To consider a variety of insulating materials for different components of building and their impact on electricity consumption.

b. To suggest the use of the most appropriate materials for the construction of building envelope to conserve maximum electricity.

To investigate these aspects and to achieve the desired objectives, the data collection methods used are: 
1. $\quad$ Case studies

2. $\quad$ Field Surveys

3. Computer Simulations

The houses selected as case studies are located in Askari-10, Lahore (Fig. 4). The newly constructed buildings reflect a housing trend of the middle-income group in Pakistan, and therefore, the solutions concluded at the end of this research will benefit a larger segment of the society to make their houses more responsive to energy demands concerning climatic variation around the year in Lahore. Three types of houses varying in sizes; in Askari-10, Lahore was studied with the help of Ecotect Software for the performance of the existing building envelope towards making the indoor temperatures comfortable for the occupants.

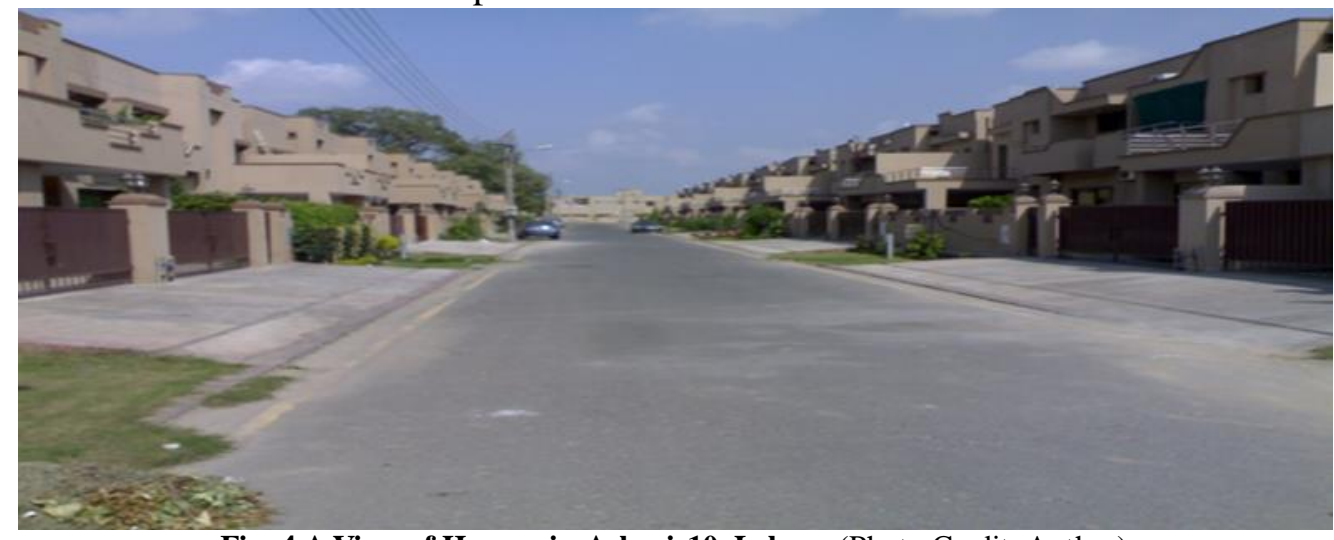

Fig. 4 A View of Houses in Askari-10, Lahore (Photo Credit: Author)

A field survey was conducted in local markets to investigate the availability of materials and construction, with a focus on materials that can perform well for making the indoor environment of a house better in a composite climate of Lahore.

Autodesk's Ecotect Analysis, an environmental analysis software tool that allows the architects and engineers in simulating the performance of the buildings, has been adopted to analyze the energy consumption of the selected residential case studies. An extensive range of stimulations can be achieved through this tool. It helps to have an analys is for evolving solutions to improve the energy efficiency of existing as well as new buildings.

This software has integrated capabilities of analyzing the consumption of energy, water, and carbon emissions. It is supplemented with characteristic properties that enable an architect to visualize and simulate a building's performance within the context of its environment and ecology (Fig. 5).

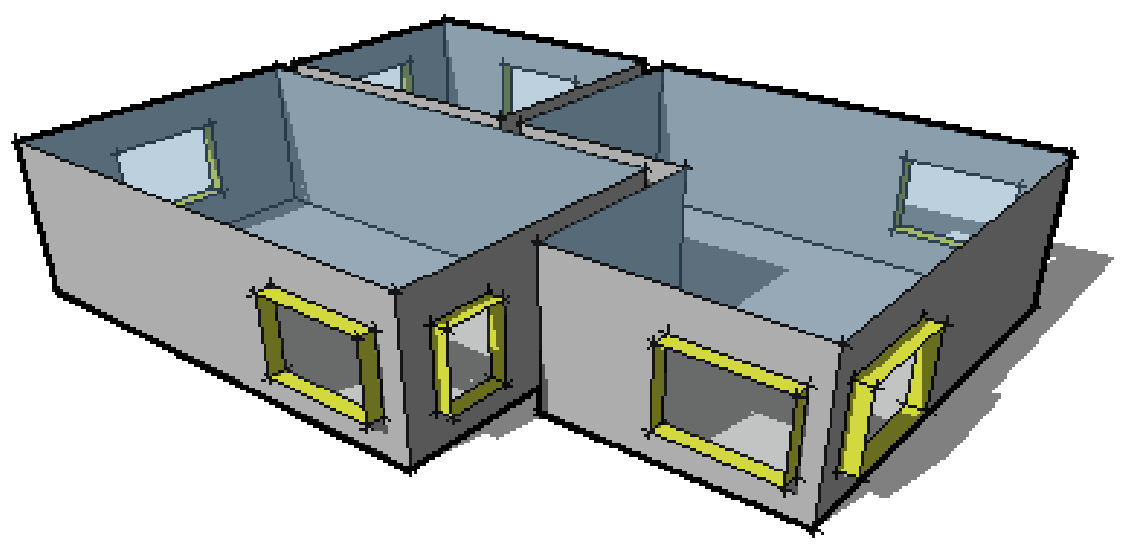

Fig. 5 Model of selected case study house Type I with extruded windows to simulate wall depth through Ecotect

\section{Limitations of Research} simulation

It was not possible to study a wide sample of residential buildings in Lahore for practical reasons. Therefore, for this research, only one residential community was studied in depth. Askari-10, which is one of the most modern housing settlements in Lahore and is fairly representative of other such 
communities. ${ }^{1}$ The typologies of houses in Askari-10 are varied, ranging in size from Type I, 12 Marlas (2700 sq. ft), (house studied here 364- C) as shown in Figure 5, to one Type II Kanal (5400 sq.ft.), (house studied here was 591-D, Askari- 10). These houses are fairly typical in plan forms and building specifications as in other parts of Lahore.

\section{Energy-Efficient Residential B uildings}

The practical application of technologies that have been used in certified green buildings varies on a regional/geographical basis, but the essential ideologies that persist from an amalgamation of derivatives deduced at the end of various practices are subjective to a regional basis. In this way a combination of measures is consequential, comprising of overall structural design efficiency, water efficiency, energy efficiency, the material used, indoor/outdoor environment, operations, and maintenance optimization that include some of the very important design efficiency concepts. As per reference of the Land Use Policy Manual designed for Australia in 2000, the main focus of the building design is to provide comfort to the occupants and minimize the energy use required to heat, cool, and light the building.

In 1991 United Nations strategized that energy-efficient buildings must have the lowest input energy ranks, to develop the bases of macro levels in a responsive environment that leads to the creation of energy-efficient buildings. ${ }^{2}$ Janssen (2004) states that perfection in energy efficiency is measured as actions undertaken by the stakeholders to decrease and reduce the per-unit energy use of output without compromising the services of the building.

\section{Discussion \& Results:}

Having justified needs for energy efficiency in selected case studies the repercussions of fundamental principles to bring about building designs with less consumption of energy are recommended below; so that the conservation potential of energy is achieved in existing houses in Lahore.

\section{a. Planning Aspects:}

Planning an energy-efficient house should take into account zoning, sizes, and orientation of different spaces of any house. It also includes considering passive solar techniques regarding the location of buildings and climate. The features to be imperatively incorporated for energy-efficient design are site investigation, a form of building, the orientation of the building, and landscaping.

\section{b. Energy Efficient B uilding Envelope}

All the opaque and semi-opaque elements of the building, which from its built line of enclosure marking its interior from exterior, are the building envelope. It is a complex job to decide materials for building envelope because it has to cater to contradicting requirements in the diverse climate of Lahore. The productivity of an effective building envelope is measured through less dependency on mechanical services to maintain the indoor climate of a house. The building envelope consists of features to achieve optimum thermal comfort. These features include the external walls, thermal insulation, doors, foundations, roof slabs, floor slabs, and windows - the components that all form a building's envelope.

\section{c. Mechanical Systems.}

The internal heat gains produced by household chores such as cooking, laundry, lighting, and air conditioning should be quantified in spaces where they apply. Installation of a mechanical system and periodic up-gradation of these systems in houses is mandatory for a reduction in energy loads. The fundamental performance in achieving a reduction of energy demand makes a building energy efficient.

The energy-efficient building designs are achieved through strategies for lighting and central air conditioning system and this can save nearly $70 \%$ of consumed energy in comparison to otherwise conventional methodologies of non-responsive building designs. Retrofitting provisions are recommended regarding HVAC systems (air conditioning) and to save around 50\% of energy consumption in already constructed buildings.

\footnotetext{
${ }^{1}$ Middle - income group of Pakistan prefers to live in gated communities for their strong security arrangements. Askari-10 beholds a good status amongst contemporary housing schemes of Lahore in this regard.

${ }^{2}$ Jones (1987) Environmentally Responsive Design pg.4 after declaring sustainable buildings to be the motto of year energy efficiency was given attention at United Nations platform.
} 


\section{d. Selection of Materials}

The indigenous materials of construction are considered to be energy efficient for buildings to reduce the embedded energy in transportation. The selection of materials must be made with two prehand considerations:

\section{$>\quad$ The energy efficiency of building materials. \\ $>\quad$ Thermal mass}

As far as the energy efficiency of building materials is concerned, the on-site manufacturing of materials has good impacts on the performance of materials as it reduces waste, creates maximum recyclable materials, and reduces transportation costs. While selecting construction materials, during the design as well as construction phase, the preference is given to materials with zero or low VOC (volatile organic compounds/ chemicals) emissions, and thus, affects the overall thermal efficiency of built structures. Many of the building materials produce toxic gases which are harmful to the environment. These gases have a damaging impact on the health of occupants and are also hazardous to comfort and functionality.

Thermal mass, on the other hand, is defined as the capacity of building materials to stock heat. The building materials with high thermal mass value can store large heat content regardless of variation in temperatures. For the regions having temperature differences between day \& night as more than $8^{\circ} \mathrm{C}$, the internal temperatures can be brought to a very moderate level by using thermal mass appropriately to avoid day and night temperature extremes.

The concrete floors have a maximum capacity to absorb heat during the day, they release heat in the best possible way when it is night-time when room windows are oriented towards the north. For this, a balanced environment is required to achieve the required thermal mass concerning the indoor and outdoor environment achieved through window sizes, orientation, and insulation levels. Thermal mass used at poor level leads to absorption of more heat gain during day and radiation of more heat during night affecting the comfort level of occupants.

\section{Applications of Proposed Energy Efficiency Techniques on Base Case Houses}

The thermal analysis of built houses was conducted by studying the ir architectural elements. It would have been challenging to calculate technical specifications for structural elements such as room volume, a floor area, or efficiency of windows in a built space; if the correct software was not used. All components in a building envelope are responsible for the amount of heat gain or loss and wind traveling in and out of the building. However, the highest potential of energy conservation lies in the walls and roofs of buildings as they are the most exposed parts to external environmental conditions such as solar radiation, air temperature, wind, and precipitation. After taking all the relevant readings through Ecotect for electricity consumption /cooling loads the insulation material as one inch to 2 inches thick polystyrene medium density was proposed for roof insulation and one-inch polystyrene as insulation material to 9 inches brick wall will reduce the electricity consumption to $34 \%$ as compared to electricity consumption within the existing building envelopes. A reduction in electric ity usage will ultimately result in a decrease in GHG emissions in the environment.

\section{Conclusions:}

The building envelope affects the overall performance of a structure and this includes walls, roofs, and glazing of a building. The construction materials used for walls and roofs available in markets having high heat conduction values and heat-storing capacity cause a major impact on the indoor thermal environment. Henceforth, it is recommended to use appropriate insulating materials that perform well towards climatic requirements and reduce the energy loads. The relevant use of simulation in post- and pre-construction phases can evaluate the building's performance and must be conducted; not only as an additional measure but it should be an absolute policy to use the software for designing to validate the actual consumption of energy in a house. This is mandatory for establishing the energy conservation potential through using the correct materials of construction along with accurate specifications in composite climates, such as that of Lahore.

Insulation with high-quality performance should be executed in a house to achieve a decrease in energy use while sustaining thermal comfort indoors. With ongoing energy issues and contemporary residential buildings not responding to climatic requirements - as experienced in selected case studies - the design parameters must be standardized for building envelopes for their validity to cut down reliance on mechanical means for cooling loads of a house. The architectural design solutions through simulations can pre-decide the selection of insulation and construction 
materials for building envelopes of houses. Such practices should be adopted as policy measures in the construction industry. The reduced consumption of energy by residential buildings will contribute largely towards conserving the energy reservoirs that are otherwise rapidly depleting, and will, therefore, also result in a reduction of carbon emissions.

\section{References:}

Ahmad A., Zhao Y., Shahbaz M., Bano S., Zhang Z., Wang S., \& Liu Y. (2015). Carbon emissions, energy consumption, and economic growth: An aggregate and disaggregate analysis of the Indian economy. Energy Policy, 96, 131-143

Ali A., Khatoon S, Ather M., and Akhtar N. (2015). Modeling energy consumption, carbon emission, and economic growth: Empirical analysis for Pakistan. International Journal of Energy Economics and Policy, 5(2), 624-630

Alshehry AS, and Belloumi M (2015). Energy consumption, carbon dioxide emissions, and economic growth: the case of Saudi Arabia. Renew Sust Energ Rev 41:237-247

Apergis N, Payne JE, Menyah K, and Wolde-Rufael Y (2010). On the causal dynamics between emissions, nuclear energy, renewable energy, and economic growth. Ecol Econ 69(11):22552260

Arouri MEH, Youssef AB, M'henni H, and Rault C (2012). Energy consumption, economic growth, and $\mathrm{CO}_{2}$ emissions in the Middle East and North African countries. Energy Policy 45:342349

Balsalobre-Lorente D, Shahbaz M, Roubaud D, and Farhani S (2018). How economic growth, renewable electricity, and natural resources contribute to $\mathrm{CO}_{2}$ emissions. Energy Policy, 113, 356-367

Hanif I (2018). Impact of economic growth, non-renewable and renewable energy consumption, and urbanization on carbon emissions in sub-Saharan Africa. Environ Sci Pollut Res 25(15):15057-15067

Jebli MB, and Youssef SB (2015). Economic growth, combustible renewables, and waste consumption, and CO2 emissions in North Africa. Environ Sci Pollut Res 22(20):1602216030

Khan M.K, Teng J.Z, Khan M.I, and Khan M.O. (2019). Impact of globalization, economic factors, and energy consumption on $\mathrm{CO}_{2}$ emissions in Pakistan. Science of the total environment, 688, 424-436

Pao HT, and Tsai CM (2010). $\mathrm{CO}_{2}$ emissions, energy consumption, and economic growth in BRIC countries. Energy Policy 38(12): 7850-7860

Shahbaz M, Uddin G.S, Rehman I.U, and Imran K (2014). Industrialization, electric ity consumption, and $\mathrm{CO}_{2}$ emissions in Bangladesh. Renewable and Sustainable Energy Reviews, 31, 575-586

Siddiqui R (2004). Energy and economic growth in Pakistan. Pak Dev Rev 175-200

Zoundi $\mathrm{Z}$ (2017). $\mathrm{CO}_{2}$ emissions, renewable energy, and the environmental Kuznets curve, a panel integration approach. Renew Sust Energ Rev 72:1067-107 